\title{
Assessment of Degradation Behavior for Acetylsalicylic Acid Using a Plasma in Liquid Process
}

\author{
Hye-Jin Bang ${ }^{1}$, Heon Lee ${ }^{1}$, Young-Kwon Park ${ }^{2}$, Hyung-Ho Ha ${ }^{3}$, Young Hyun Yu ${ }^{3}$, \\ Byung-Joo Kim ${ }^{4}\left(\mathbb{D}\right.$ and Sang-Chul Jung ${ }^{1, *(\mathbb{D}}$ \\ 1 Department of Environmental Engineering, Sunchon National University, 255 Jungang-ro, Suncheon, \\ Jeonnam 57922, Korea; jinny1185015@naver.com (H.-J.B.); honylee@hanmail.net (H.L.) \\ 2 School of Environmental Engineering, University of Seoul, 163 Seoulsiripdaero, Dongdaemun-gu, \\ Seoul 02504, Korea; catalica@uos.ac.kr \\ 3 College of Pharmacy, Sunchon National University, 255 Jungang-ro, Suncheon, Jeonnam 57922, Korea; \\ hhha@sunchon.ac.kr (H.-H.H.); chmyyh@gmail.com (Y.H.Y.) \\ 4 Carbon Valley R\&D Division, Korea Institute of Carbon Convergence Technology, 110-11 Banryong-ro, \\ Jeonju 54853, Korea; kimbj2015@gmail.com \\ * Correspondence: jsc@sunchon.ac.kr; Tel.: +82-61-750-3814
}

Received: 2 November 2019; Accepted: 15 November 2019; Published: 16 November 2019

\begin{abstract}
Acetylsalicylic acid (ASA) is a pharmacologically active compound. In this study, ASA was decomposed effectively using a plasma in liquid phase process with hydrogen peroxide and $\mathrm{TiO}_{2}$ photocatalyst. Increasing the electrical power conditions (frequency, applied voltage, and pulse width) promoted plasma generation, which increased the rate of ASA decomposition. The added hydrogen peroxide increased the rate of ASA degradation, but injecting an excess decreased the degradation rate due to a scavenger effect. Although there was an initial increase in the decomposition efficiency by the addition of $\mathrm{TiO}_{2}$ powder, the addition of an excessive amount inhibited the generation of plasma and decreased the degradation rate. The simultaneous addition of $\mathrm{H}_{2} \mathrm{O}_{2}$ and $\mathrm{TiO}_{2}$ powder resulted in the highest degradation efficiency. We suggest that ASA is converted to salicylic acid through demethylation by hydroxyl radicals and is finally mineralized to carbon dioxide and water via 2,4-dihydroxy benzoic acid and low molecular acids.
\end{abstract}

Keywords: acetylsalicylic acid; plasma in liquid phase process; hydrogen peroxide; $\mathrm{TiO}_{2}$ photocatalyst; decomposition mechanism

\section{Introduction}

In modern society, pharmaceutical organic compounds (POCs) are released into the aquatic environment without appropriate treatment. These drugs and their resulting intermediates can cause a range of health and environmental problems [1,2]. Acetylsalicylic acid (ASA), also known as aspirin, is a nonsteroidal anti-inflammatory drug (NSAID) commonly used for pain relief [3]. Aspirin is also used widely as an antipyretic agent and an anti-inflammatory to treat fever and heart attacks, but high doses can have undesirable side effects, such as gastrointestinal ulcers, gastric bleeding, and tinnitus [4]. Exposure to aquatic environments can lead to its degradation to a range of toxic intermediates in aqueous media, which can cause environmental pollution and adversely affect human health. Traditional techniques of disposal (adsorption, ozonization, etc.) generate concentrated wastewater and gaseous emissions, which are harmful to humans and the environment and must be treated fully before being discharged to landfill and rivers [5]. Therefore, effective strategies are needed to address the environmental problems associated with aspirin contamination.

Methods of removing POCs, such as aspirin in the environment, include several traditional treatment methods (biological, physical, and chemical processes) and advanced oxidation processes 
(AOPs) [6,7]. AOPs can effectively remove difficult to decompose water contaminants, replacing traditional water treatment methods [8,9]. AOPs use hydroxyl radicals through a process that combines the Fenton reaction, $\mathrm{TiO}_{2}$ photocatalyst, zero-valent iron, $\mathrm{UV}, \mathrm{H}_{2} \mathrm{O}_{2}$, and ozone [10-12].

Among them, the $\mathrm{TiO}_{2}$ photocatalyst system has been studied widely as a low-cost, safe, chemically stable, and environmentally friendly process. On the other hand, the low reaction rate and relatively non-selective reaction has limited its application to industry. In particular, when treating contaminants in water using $\mathrm{TiO}_{2}$ powder, it is difficult to recover the $\mathrm{TiO}_{2}$ powder after the treatment step. Thus, attempts have been made to add or combine other processes to improve the efficiency of the photocatalytic reaction.

Recently, researches using plasma generated in the liquid phase to treat organic compounds in water have been actively conducted $[13,14]$. In addition to hydrogen radicals, many strongly oxidative reactive species $\left(\mathrm{O},{ }^{1} \mathrm{O}_{2}, \mathrm{O}_{3}, \mathrm{HO}_{2}, \mathrm{H}_{2} \mathrm{O}_{2}\right.$, etc.) in the plasma generated in the liquid solution can be used to effectively break down organic compounds to $\mathrm{CO}_{2}$ and $\mathrm{H}_{2} \mathrm{O}$. In this study, a plasma in liquid process (PiLP) was performed to decompose ASA effectively in water, and the effects of the plasma process variables on the decomposition reaction were examined. In addition, $\mathrm{H}_{2} \mathrm{O}_{2}$ aqueous solution and $\mathrm{TiO}_{2}$ photocatalyst were added to the PiLP to improve the efficiency of ASA degradation. The reaction intermediates from ASA degradation by the PiLP were analyzed by high performance liquid chromatography combined with a mass spectrometer (HPLC-MS). Based on this, the mechanism of ASA decomposition by a PiLP reaction is presented.

\section{Results and Discussion}

\subsection{Effect of the Plasma Operating Conditions}

The influence of the electrical power variables (frequency, pulse width, and applied voltage) applied to the PiLP on the ASA degradation reaction was evaluated. Figure 1 shows the influence of varying the electrical power conditions on the ASA decomposition rate. In addition, the change in the hydroxyl radicals generated under each electrical power condition was measured by an optical emission spectrometer (OES); the results are shown on the right side of Figure 1. Figure 1a presents the ASA degradation rates for each of the applied voltages (200, 225 and $250 \mathrm{~V})$, wherein the pulse width and frequency of the power supply were fixed to $5 \mu$ s and $30 \mathrm{kHz}$, respectively. As the voltage applied to the PiLP increased, the decomposition efficiency of ASA increased. In particular, the decomposition rate increased significantly at $250 \mathrm{~V}$. When electrical energy is applied through the tungsten electrode installed in the center of the PiLP reactor, plasma is generated by dielectric breakdown of water. The generated electrons $\left(\mathrm{e}^{-}\right)$react with water to produce chemically active species, and the OES spectra results show hydroxyl radicals $(309 \mathrm{~nm})$, hydrogen radicals $(486 \mathrm{~nm}$ and $656 \mathrm{~nm})$, and oxygen radicals (777 $\mathrm{nm}$ and $845 \mathrm{~nm}$ ). Note that these are created [15-18]. Therefore, the applied voltage affects the amount of chemically active species generated by the plasma reaction. In contrast, the emission intensity of hydroxyl radicals produced at $250 \mathrm{~V}\left(2.48 \times 10^{4}\right)$, measured by OES, was approximately two times greater than that at $200 \mathrm{~V}\left(1.25 \times 10^{4}\right)$, as shown in Figure $1 \mathrm{~b}$. In this study, the degradation reaction of ASA by the PiLP was assumed to be pseudo first order, and the decomposition rate constant $k$ of ASA was calculated as a function of the applied voltage. As a result, $k$ at $200 \mathrm{~V}, 225 \mathrm{~V}$, and $250 \mathrm{~V}$ was found to be $4.28 \times 10^{-3} / \mathrm{min}, 5.91 \times 10^{-3} / \mathrm{min}$, and $9.78 \times 10^{-3} / \mathrm{min}$, respectively. These results show that the rate of ASA degradation was affected by the quantity of hydroxyl radicals generated. Therefore, applied voltage is a major process variable in ASA decomposition in the PiLP.

To examine the change in the ASA decomposition rate according to frequency, which is one of the power supply conditions, the frequency was changed from 21 to $30 \mathrm{kHz}$ in $3 \mathrm{kHz}$ intervals, while the pulse width and voltage were fixed to $5 \mu$ s and $250 \mathrm{~V}$, respectively. Figure $1 \mathrm{c}$ shows the rate of ASA decomposition according to the frequency change. Figure 1d presents the emission intensity of the hydroxyl radicals generated at each frequency. It may be seen that the rate of ASA degradation increased with increasing frequency. In particular, the rate of ASA degradation 
increased rapidly at $30 \mathrm{kHz}$. In this study, a bipolar pulsed-type power supply was applied, and the energy (E) supplied to the tungsten electrode per second may be expressed as the energy per pulse $\left(E_{p}\right) \times$ frequency. As the frequency increases, the energy supplied to the plasma field increases, thereby increasing the generation of chemically active species in the plasma field-particularly hydroxyl radicals $[19,20]$. The emission intensities of the hydroxyl radicals shown in Figure $1 \mathrm{~d}$ were measured at $21 \mathrm{kHz}\left(0.81 \times 10^{4}\right), 24 \mathrm{kHz}\left(1.21 \times 10^{4}\right), 27 \mathrm{kHz}\left(1.56 \times 10^{4}\right)$, and $30 \mathrm{kHz}\left(2.48 \times 10^{4}\right)$. The rate constants $k$ of ASA degradation measured at 21, 24, 27, and $30 \mathrm{kHz}$ were $2.24 \times 10^{-3} / \mathrm{min}, 3.54 \times 10^{-3} / \mathrm{min}$, $5.62 \times 10^{-3} / \mathrm{min}$, and $9.78 \times 10^{-3} / \mathrm{min}$, respectively. Compared to $21 \mathrm{kHz}$, the decomposition rate at $30 \mathrm{kHz}$ was improved approximately 2.8 fold. Hence, frequency is an important reaction factor in the ASA decomposition reaction.

(a)

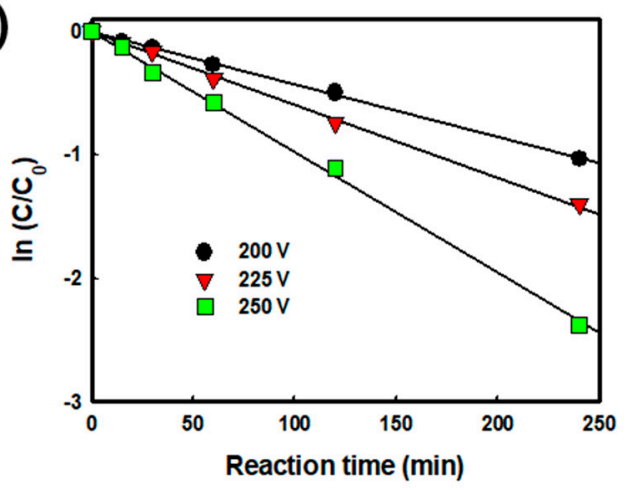

(c)

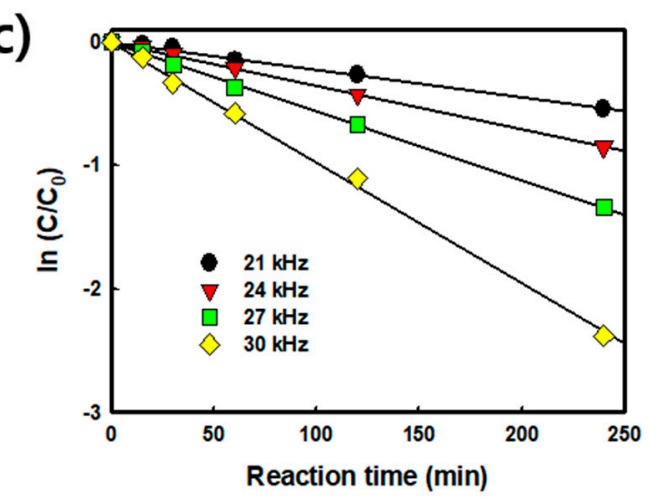

(e)

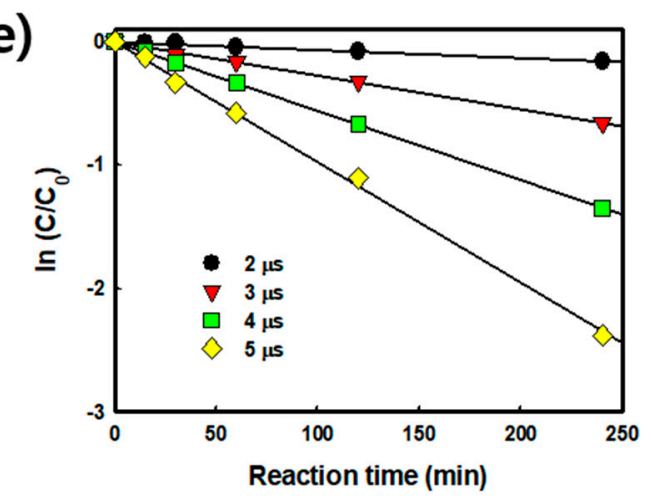

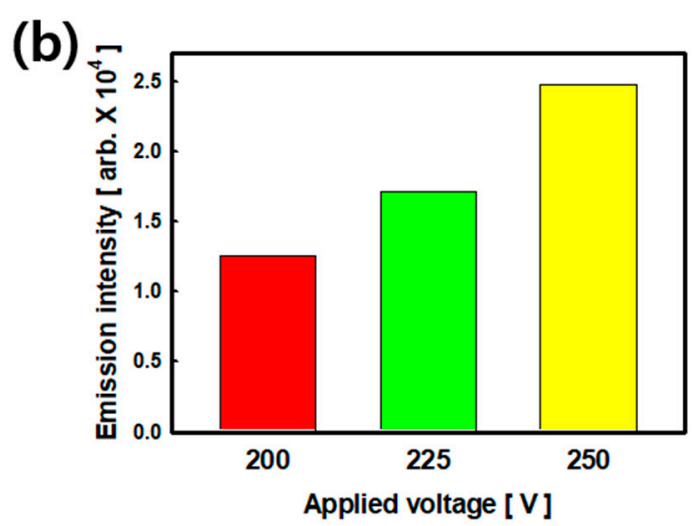
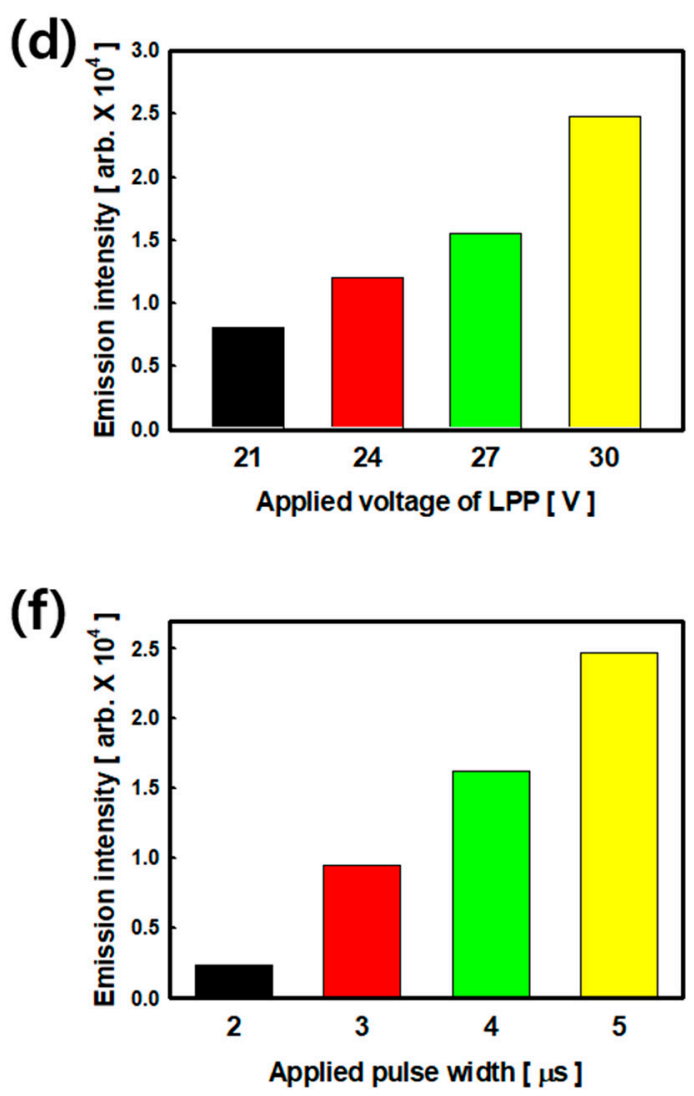

Figure 1. Degradation rate of ASA $(\mathbf{a}, \mathbf{c}, \mathbf{e})$ and the emission intensity of hydroxyl radicals $(\mathbf{b}, \mathbf{d}, \mathbf{f})$ according to the electrical power condition of the PiLP: variation of applied voltage $(\mathbf{a}, \mathbf{b})$; variation of frequency $(\mathbf{c}, \mathbf{d})$; variation of pulse width $(\mathbf{e}, \mathbf{f})$. 
Figure 1e shows the change in the decomposition efficiency of ASA using a pulse width of $2 \mu \mathrm{s}$ to $5 \mu \mathrm{s}$, where the applied frequency and voltage were maintained at $30 \mathrm{kHz}$ and $250 \mathrm{~V}$, respectively. At a pulse width of $2 \mu \mathrm{s}$, almost no ASA decomposition occurred, and the formation of plasma was unstable in the PiLP reactor. Plasma was formed stably from pulse widths above $3 \mu$ s, and the rate of ASA degradation increased with increasing pulse width. Figure $1 \mathrm{f}$ shows the emission intensity of hydroxyl radicals produced as a function of the pulse width. The emission intensity was very low at a pulse width of $2 \mu \mathrm{s}\left(0.24 \times 10^{4}\right)$, but it increased with increasing pulse width: $3 \mu \mathrm{s}\left(0.96 \times 10^{4}\right)$, $4 \mu \mathrm{s}\left(1.62 \times 10^{4}\right)$ and $5 \mu \mathrm{s}\left(2.48 \times 10^{4}\right)$. In this experiment, the bipolar pulse method applied to prevent continuous corrosion of the electrode was formed from one pulse to two pulses on time (positive and negative), where the pulse width corresponded to one pulse on time [21]. If the pulse width is $2 \mu \mathrm{s}$ at $30 \mathrm{kHz}$, the duty ratio is 0.12 . At $5 \mu \mathrm{s}$, the duty ratio is 0.30 , which increases the power supply time required for plasma generation in the aqueous solution. Increasing the pulse width increases the time for supplying electrical energy from the power supply, which facilitates plasma generation. Hence, the rate of ASA degradation increases due to the increased production of chemically active species. The rate constants $k$ for ASA degradation at pulse widths of $2 \mu \mathrm{s}, 3 \mu \mathrm{s}, 4 \mu \mathrm{s}$, and $5 \mu \mathrm{s}$ were $0.67 \times 10^{-3} / \mathrm{min}, 2.74 \times 10^{-3} / \mathrm{min}, 5.61 \times 10^{-3} / \mathrm{min}$, and $9.78 \times 10^{-3} / \mathrm{min}$, respectively.

\subsection{Effect of $\mathrm{H}_{2} \mathrm{O}_{2}$}

The effects of hydrogen peroxide addition on the degradation of ASA in the PiLP was also investigated. Figure 2 shows the rate of ASA degradation according to $\mathrm{H}_{2} \mathrm{O}_{2}$ concentration in the aqueous reactant solution. The $\mathrm{H}_{2} \mathrm{O}_{2}$ concentration in the ASA solution varied from 0.001 to $0.100 \mathrm{M}$. The electrical power conditions were maintained at $250 \mathrm{~V}, 30 \mathrm{kHz}$, and $5 \mu \mathrm{s}$. With the exception of the addition of $0.1 \mathrm{M} \mathrm{H}_{2} \mathrm{O}_{2}$, the rate of ASA decomposition was greater with $\mathrm{H}_{2} \mathrm{O}_{2}$ added than with no addition. The added $\mathrm{H}_{2} \mathrm{O}_{2}$ reacts with light or electrons $\left(\mathrm{e}^{-}\right)$in the plasma field to produce hydroxyl radicals [22-25]. In addition, $\mathrm{H}_{2} \mathrm{O}_{2}$ itself can participate in the decomposition of ASA. The rate constants $k$ of ASA degradation according to the addition of $\mathrm{H}_{2} \mathrm{O}_{2}$ were $10.34 \times 10^{-3} \mathrm{~min}^{-1}(0.001 \mathrm{M})$, $11.81 \times 10^{-3} \mathrm{~min}^{-1}(0.010 \mathrm{M})$, and $13.54 \times 10^{-3} \mathrm{~min}^{-1}$, showing 6-38\% improvement compared to the ASA decomposition rate $\left(9.78 \times 10^{-3} \mathrm{~min}^{-1}\right)$ by the PiLP alone. On the other hand, when $0.100 \mathrm{M}$ of $\mathrm{H}_{2} \mathrm{O}_{2}$ was added, the ASA degradation rate constant $k$ decreased considerably to $8.87 \times 10^{-3} \mathrm{~min}^{-1}$. Excess $\mathrm{H}_{2} \mathrm{O}_{2}$ in the reaction solution acts as a scavenger that reacts with hydroxyl radicals generated by the PiL reaction to form hydroperoxyl radicals and $\mathrm{O}_{2}$ and $\mathrm{H}_{2} \mathrm{O}$ [26]. Overall, the addition of hydrogen peroxide to the decomposition reaction of ASA using the PiLP method improves the decomposition rate, but it is important to add the appropriate amount.

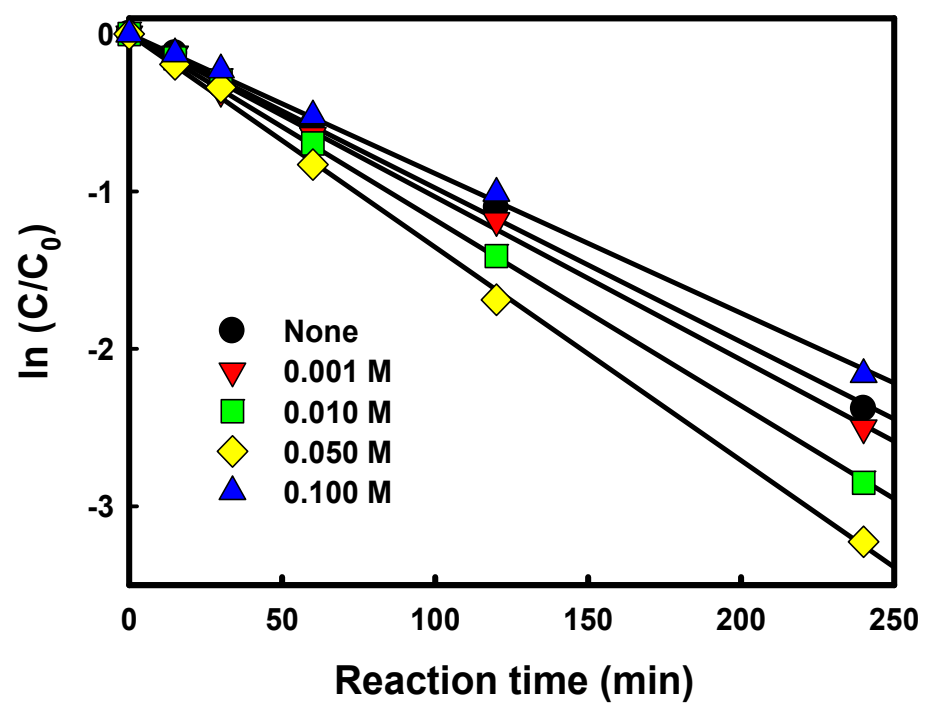

Figure 2. Degradation rate of ASA measured at various hydrogen peroxide addition amounts. 


\subsection{Effect of $\mathrm{TiO}_{2}$ Photocatalyst}

$\mathrm{TiO}_{2}$ photocatalyst was also added to the PiLP reactor to improve the decomposition efficiency of ASA. Figure 3 shows the degradation rate of ASA when $\mathrm{TiO}_{2}$ photocatalyst powder (P25) was added at $0.05-0.50 \mathrm{~g} / \mathrm{L}$. In this experiment, the electrical power conditions were maintained at the same optimum conditions $(250 \mathrm{~V}, 30 \mathrm{kHz}$, and $5 \mu \mathrm{s})$. The addition of 0.05 to $0.20 \mathrm{~g} / \mathrm{L}$ of P25 improved the rate of ASA degradation compared to that obtained in the absence of $\mathrm{P}_{25}$. $\mathrm{TiO}_{2}$ photocatalyst is activated by UV generated at the tungsten electrode, and the decomposition of ASA is achieved by hydroxyl radicals and strong oxidants generated on the activated photocatalytic surface $[27,28]$. When P25 was used at $0.05 \mathrm{~g} / \mathrm{L}$ and $0.10 \mathrm{~g} / \mathrm{L}$, the ASA degradation rate constants $k$ was $10.986 \times 10^{-3} / \mathrm{min}$ and $13.24 \times 10^{-3} / \mathrm{min}$, respectively, corresponding to a $12 \%$ and $35 \%$ increase compared to that without P25 $\left(9.78 \times 10^{-3} \mathrm{~min}^{-1}\right)$. On the other hand, when $0.20 \mathrm{~g} / \mathrm{L}$ and $0.50 \mathrm{~g} / \mathrm{L}$ of P25 was used, $k$ decreased slightly to $11.78 \times 10^{-3} / \mathrm{min}$ and $8.73 \times 10^{-3} / \mathrm{min}$, respectively. Increasing the amount of P25 in the reactant aqueous solution reduces the amount of light radiation, which decreases the formation of plasma channels between the PiLP electrodes. Therefore, excessive addition of P25 powder makes it difficult to generate plasma, thereby lowering the rate of ASA decomposition [28].

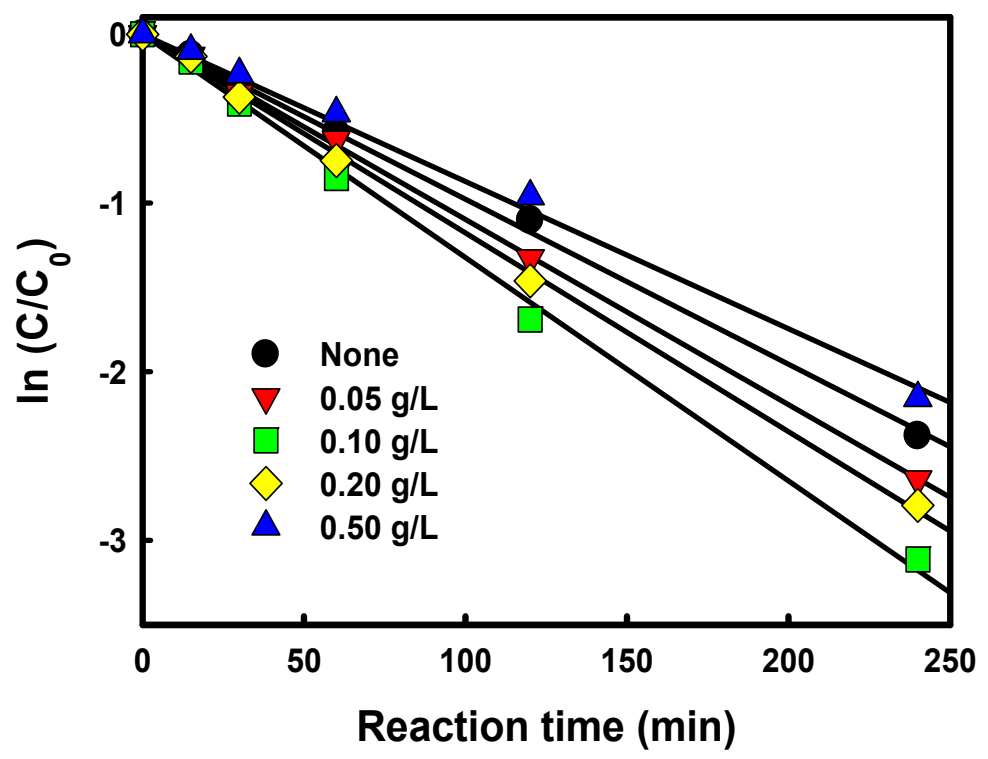

Figure 3. Degradation rate of ASA measured at various $\mathrm{TiO}_{2}$ photocatalyst addition amounts.

\subsection{Effect of a Combination of Reaction Processes}

The effects of a combination of the PiLP and other unit processes on the degradation of ASA were compared. Figure 4 shows the change of rate constants by the addition of hydrogen peroxide and $\mathrm{TiO}_{2}$ photocatalyst in ASA decomposition using the PiLP. Here, 'PiLP' is the case using only the PiLP, 'PiLP-H' is the process of adding hydrogen peroxide $(0.05 \mathrm{M})$ to the PiLP, and 'PiLP-T' is the process of adding $\mathrm{TiO}_{2}$ photocatalyst $(0.10 \mathrm{~g} / \mathrm{L})$. The case of 'PILP-HT' is also shown, and is the process in which $\mathrm{TiO}_{2}$ photocatalyst and $\mathrm{H}_{2} \mathrm{O}_{2}$ are added simultaneously, with the amount of additives used being the same as that of PiLP-H and PiLP-T. This experiment was performed at the same optimum electrical power conditions $(250 \mathrm{~V}, 30 \mathrm{kHz}$, and $5 \mu \mathrm{s})$. PiLP-H $\left(13.54 \times 10^{-3} \mathrm{~min}^{-1}\right)$ and PiLP-T $\left(13.24 \times 10^{-3} \mathrm{~min}^{-1}\right)$ showed higher decomposition rates than the PiLP only $\left(9.84 \times 10^{-3} \mathrm{~min}^{-1}\right)$; PiLP-H was slightly higher than PiLP-T. Furthermore, the ASA degradation rate constant of PiLP-HT was $15.67 \times 10^{-3} \mathrm{~min}^{-1}$, showing $60 \%$ improvement in reaction efficiency compared to the simple PiLP. 


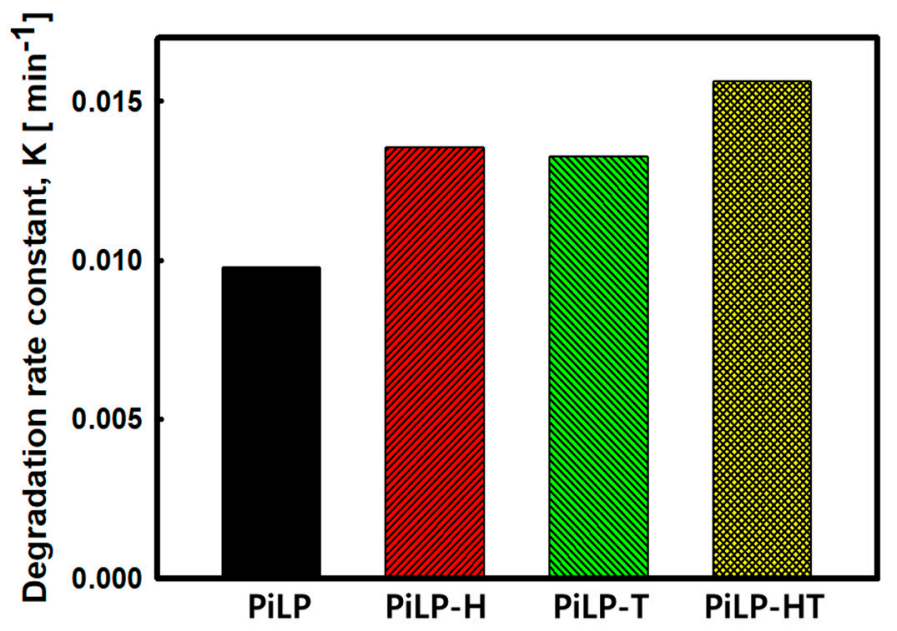

Figure 4. Comparison of the ASA decomposition rates obtained under various experimental conditions.

\subsection{Degradation Reaction Pathway of ASA by the PiLP}

Intermediates generated during ASA degradation by the PiLP were measured by liquid chromatography-mass spectrometry (LC-MS) analysis to examine the mechanism of the degradation reaction. Figure 5 shows the LC-MS chromatogram (left) of the sample obtained from the ASA digestion reaction for 30 and 240 minutes using the PiLP, together with the name and chemical structure of the compounds detected. Peaks were detected at retention times of $20.56 \mathrm{~min}$ (1) and $24.81 \mathrm{~min}$ (2). In this study, LC-MS was conducted in negative ion mode, where $179 \mathrm{~m} / \mathrm{z}$ and $137 \mathrm{~m} / \mathrm{z}$ were assigned to ASA and salicylic acid (SA), respectively [29]. The peak intensities of ASA and SA decreased with increasing reaction time; thus, the PiLP decomposed the degradation compounds and intermediates.

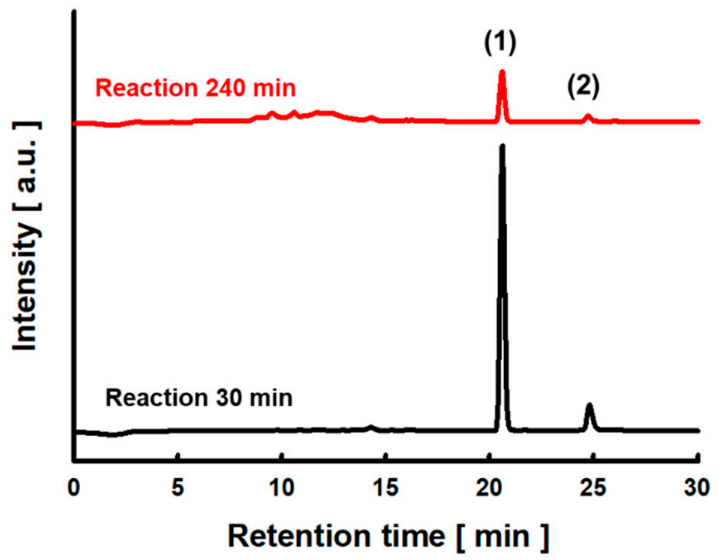

(1) Acetylsalicylic acid (ASA)

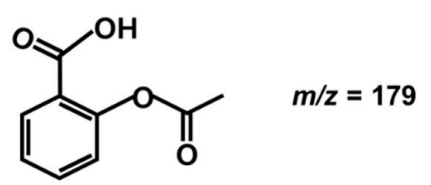

(2) Salicylic acid (SA)<smiles>O=C(O)c1ccccc1O</smiles>
$m / z=137$

Figure 5. Liquid chromatography-mass spectrometry (LC-MS) chromatogram according to the reaction time of PiLP and name and chemical structure of measured compound by LC-MS.

Based on the results obtained through LC-MS analysis, Figure 6 presents the possible degradation pathway of ASA by the PiLP. Chemically active species, particularly hydroxyl radicals, generated in the PiLP attack the $\mathrm{C}=\mathrm{O}$ bonds of ASA to produce salicylic acid (2) by demethylation [30]. Through hydroxyl radicals, the aromatic ring of salicylic acid is converted to the $\mathrm{OH}$-adduct, 2,4-dihydroxybenzoic acid (3), which is then converted to maleic acid (4) and fumaric acid (5) through ring opening [31,32]. These compounds are then decomposed to low molecular acids, such as oxalic acid (OA), succinic acid (SA), and formic acid (FA), and finally to $\mathrm{CO}_{2}$ and $\mathrm{H}_{2} \mathrm{O}[30,33]$. 
(1)

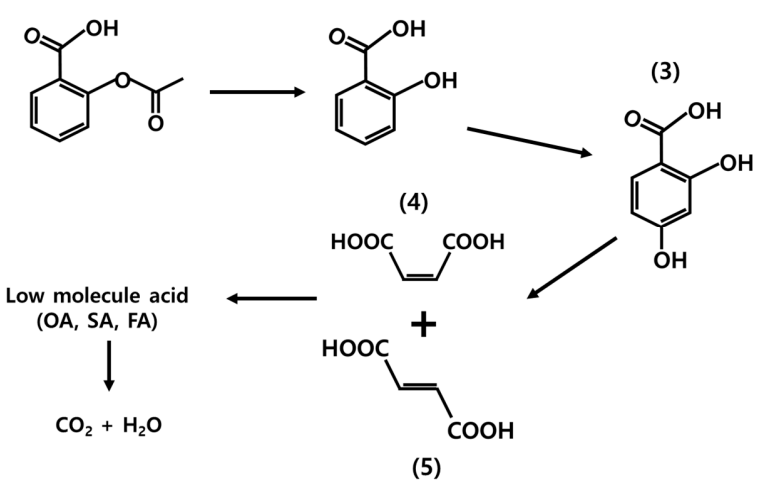

Figure 6. The proposed degradation mechanism of ASA by PiLP.

\section{Materials and Methods}

\subsection{Materials and Equipment}

Acetylsalicylic acid $\left(\mathrm{C}_{9} \mathrm{H}_{8} \mathrm{O}_{4}\right.$, ASA) was purchased from Sigma Aldrich, Saint Louis, MO, USA. Deionized (DI) water (conductivity $\leq 2 \mu \mathrm{S} / \mathrm{cm}$, Daejung chemicals, Siheung, Korea) was used to prepare the reactant aqueous solutions. $\mathrm{TiO}_{2}$ photocatalyst powder (P25, consisting of $85 \%$ anatase and $15 \%$ rutile), which was added to improve the decomposition efficiency of the PiLP, was acquired from Degussa, Essen, North Rhine-Westphalia, Germany. Hydrogen peroxide $\left(\mathrm{H}_{2} \mathrm{O}_{2}\right.$, assay $\left.35 \%\right)$ was obtained from Daejung Chemicals, Siheung, Korea. All chemicals were used as received.

Figure 7 is a diagram of the PiLP experimental apparatus used in the ASA degradation reaction. The PiLP system consisted of a power supply, a reactor, a reaction water tank and a constant temperature bath. The power supply (NTI-1000W, Nanotechnology, Co. Ltd., Daejeon, Korea) was a high frequency bipolar pulse type that converted AC $(220 \mathrm{~V})$ into direct current (DC) and supplied it to the reactor (power was set to $1 \mathrm{~kW}$ ). In this experiment, the voltage of the power generator was changed from 200 to $250 \mathrm{~V}$. The pulse width and frequency of the generator was tested in the range, $2-5 \mu$ s and 21-30 kHz, respectively. The PiLP reactor was a double tube type circular reactor (OD $100 \mathrm{~mm}$, ID $86 \mathrm{~mm}, \mathrm{H} 150 \mathrm{~mm}$ ) with an ASA reaction solution inside. The tungsten electrode (diameter $2 \mathrm{~mm}$, purity 99.95\%), which was placed in the center of the PiLP reactor and surrounded by a ceramic insulator, had a gap of $1 \mathrm{~mm}$ at all times. The outside of the PiLP reactor was connected to the circulation refrigerator to prevent a reaction solution temperature rise by the PiLP reaction, the reaction solution temperature was maintained at $20^{\circ} \mathrm{C}$.

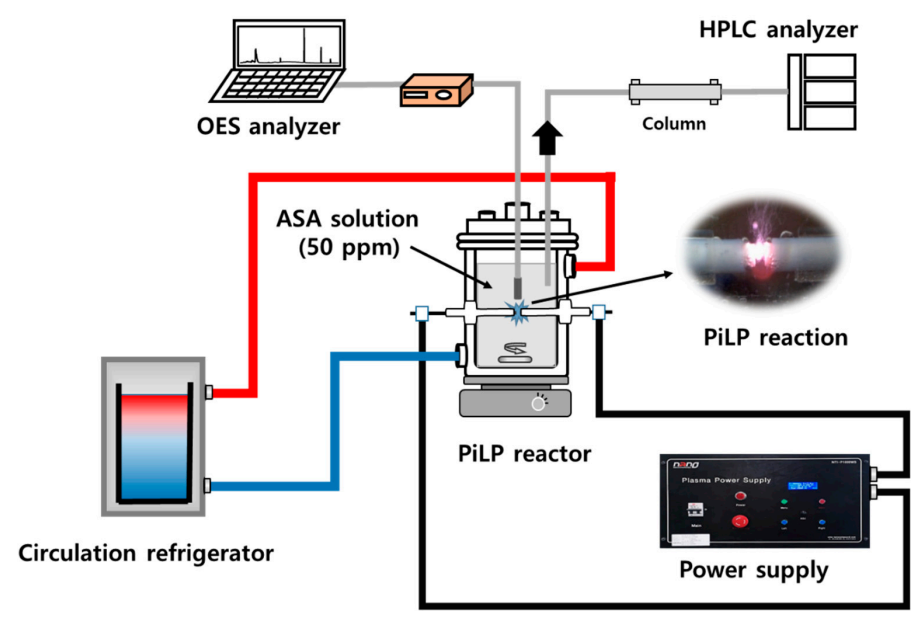

Figure 7. Schematic of the PiLP system for degradation of ASA. 


\subsection{Experimental Procedure}

The decomposition of ASA by the PiLP was carried out as follows. One liter of a $1000 \mathrm{ppm}$ aqueous ASA solution was used as the source solution, and an aqueous ASA reactant solution (50 ppm) used in the PiLP was prepared using the source solution. The prepared ASA reactant aqueous solution (300 $\mathrm{mL}$ ) was placed in the PiLP reactor, and the decomposition characteristics of the ASA were examined while changing the electrical power conditions (frequency, applied voltage, and pulse width). An optical emission spectrometer (OES, AvaSpec-3648, Avantes, Apeldoorn, Netherland) was used to compare the generation of radicals according to the electrical power conditions of the PiLP. In addition, $\mathrm{TiO}_{2}$ photocatalyst $(0.05-0.50 \mathrm{~g} / \mathrm{L})$ and hydrogen peroxide $\left(\mathrm{H}_{2} \mathrm{O}_{2}, 0.001-0.100 \mathrm{M}\right)$ were added to the PiLP reactor to improve the rate of ASA degradation. The reaction aqueous solution was collected at regular reaction times and the concentration of ASA was measured by HPLC (1260 Infinity, Agilent Tech., Santa Clara, CA, USA). The HPLC column used was C-18 $(4.6 \times 150 \mathrm{~mm}$, Agilent Tech., Santa Clara, CA, USA). The mobile phase was a mixture of $60 \%$ water containing $2 \%$ phosphoric acid and $40 \%$ acetonitrile with a flow rate of $1 \mathrm{~mL} \mathrm{~min}^{-1}$. A UV detector with a wavelength of $237 \mathrm{~nm}$ was used at the temperature of the column thermostat at $250{ }^{\circ} \mathrm{C}$. The intermediates generated during ASA degradation by the PiLP were analyzed by HPLC-MS (LC-MS 2020, Shimadzu, Kyoto, Japan). For this analysis a Shimadzu shim-pack VP-ODS C8 phenyl column was used and the samples had a volume of $25 \mu \mathrm{L}$. The mobile phase was a mixture of water $30 \%$ with $0.04 \%$ acetic acid and acetonitrile $70 \%$ with a flow rate of $0.1 \mathrm{~mL} / \mathrm{min}$. In this analysis, the instrument was operated in negative electrospray ionization (ESI) mode.

\section{Conclusions}

ASA was decomposed using the PiLP reaction with hydrogen peroxide and $\mathrm{TiO}_{2}$ photocatalyst. Increasing the electrical power conditions (frequency, applied voltage and pulse width) promoted plasma generation, which improved the rate of ASA degradation due to increased hydroxyl radicals. $\mathrm{H}_{2} \mathrm{O}_{2}$ added to the PiLP reactor increased the rate of ASA decomposition, but more than a certain amount of injection reduced the rate of decomposition by the scavenger effect. The addition of $\mathrm{TiO}_{2}$ photocatalyst also increased the efficiency of ASA decomposition, but adding large amounts prevented plasma generation, which reduced the degradation rate. The addition of hydrogen peroxide and $\mathrm{TiO}_{2}$ photocatalyst resulted in a higher decomposition rate than that of the PiLP only, and the simultaneous addition of hydrogen peroxide and $\mathrm{TiO}_{2}$ photocatalyst produced the highest decomposition efficiency. In terms of the decomposition mechanism, ASA is converted to salicylic acid by demethylation through hydroxyl radicals, and finally mineralized to carbon dioxide and water via 2,4-dihydroxy benzoic acid, maleic acid, fumaric acid, oxalic acid, succinic acid, and formic acid.

Author Contributions: H.-J.B., H.L., and S.-C.J. designed the experiments. H.-J.B. and H.L. performed the experiments and wrote the original drafted paper. Y.-K.P., H.-H.H., and Y.H.Y. contributed to the analysis and the interpretation of data. S.-C.J. and B.-J.K. edited the original drafted paper. S.-C.J. supervised the experiments and paper. All authors discussed the results and contributed to the manuscript.

Funding: This research was supported by Basic Science Research Program through the National Research Foundation of Korea (NRF) funded by the Ministry of Education (NRF-2018R1D1A1B07049595).

Conflicts of Interest: The authors declare no conflict of interest.

\section{References}

1. Luo, Y.; Guo, W.; Ngo, H.H.; Nghiem, L.D.; Hai, F.I.; Zhang, J.; Liang, S.; Wang, X.C. A review on the occurrence of micropollutants in the aquatic environment and their fate and removal during wastewater treatment. Sci. Total Environ. 2014, 473-474, 619-641. [CrossRef] [PubMed]

2. Santos, J.L.; Aparicio, I.; Alonso, E.; Callejón, M. Simultaneous determination of pharmaceutically active compounds in wastewater samples by solid phase extraction and high-performance liquid chromatography with diode array and fluorescence detectors. Anal. Chim. Acta 2005, 550, 116-122. [CrossRef] 
3. Adebayo, G.I.; Williams, J.; Healy, S. Aspirin esterase activity-Evidence for skewed distribution in healthy volunteers. Eur. J. Int. Med. 2007, 18, 299-303. [CrossRef] [PubMed]

4. Calza, P.; Sakkas, V.A.; Medana, C.; Baiocchi, C.; Dimou, A.; Pelizzetti, E.; Albanis, T. Photocatalytic degradation study of diclofenac over aqueous $\mathrm{TiO}_{2}$ suspensions. Appl. Catal. B Environ. 2006, 67, 197-205. [CrossRef]

5. Agunbiade, F.O.; Moodley, B. Occurrence and distribution pattern of acidic pharmaceuticals in surface water, wastewater, and sediment of the Msunduzi River, Kwazulu-Natal, South Africa. Environ. Toxicol. Chem. 2016, 35, 36-46. [CrossRef]

6. Na, S.; Jinhua, C.; Cui, M.; Khim, J. Sonophotolytic diethyl phthalate (DEP) degradation with UVC or VUV irradiation. Ultrason. Sonochem. 2012, 19, 1094-1098. [CrossRef]

7. Yang, G.C.C.; Huang, S.C.; Wang, C.L.; Jen, Y.S. Degradation of phthalate esters and acetaminophen in river sediments using the electrokinetic process integrated with a novel Fenton-like process catalyzed by nanoscale schwertmannite. Chemosphere 2016, 159, 282-292. [CrossRef]

8. Lee, H.; Park, S.H.; Park, Y.K.; Kim, S.J.; Seo, S.G.; Ki, S.J.; Jung, S.C. Photocatalytic reactions of 2,4-dichlorophenoxyacetic acid using a microwave-assisted photocatalysis system. Chem. Eng. J. 2015, 278, 259-264. [CrossRef]

9. Ki, S.J.; Jeon, K.J.; Park, Y.K.; Jeong, S.; Lee, H.; Jung, S.C. Improving removal of 4-chlorophenol using a $\mathrm{TiO}_{2}$ photocatalytic system with microwave and ultraviolet radiation. Catal. Today 2017, 293-294, 15-22. [CrossRef]

10. An, T.; Gao, Y.; Li, G.; Kamat, P.V.; Peller, J.; Joyce, M.V. Kinetics and Mechanism of $\bullet$ OH Mediated Degradation of Dimethyl Phthalate in Aqueous Solution: Experimental and Theoretical Studies. Environ. Sci. Technol. 2014, 48, 641-648. [CrossRef]

11. Lee, D.J.; Park, Y.K.; Kim, S.J.; Lee, H.; Jung, S.C. Photo-catalytic destruction of ethylene using microwave discharge electrodeless lamp. Korean J. Chem. Eng. 2015, 32, 1188-1193. [CrossRef]

12. Xu, B.; Gao, N.Y.; Sun, X.F.; Xia, S.J.; Rui, M.; Simonnot, M.O.; Causserand, C.; Zhao, J.F. Photochemical degradation of diethyl phthalate with $\mathrm{UV} / \mathrm{H}_{2} \mathrm{O}_{2}$. J. Hazard. Mater. 2007, 139, 132-139. [CrossRef] [PubMed]

13. Lee, H.; Park, S.H.; Park, Y.K.; Kim, B.H.; Kim, S.J.; Jung, S.C. Rapid destruction of the rhodamine B using $\mathrm{TiO}_{2}$ photocatalyst in the liquid phase plasma. Chem. Cent. J. 2013, 7, 156. [CrossRef]

14. Lee, H.; Park, S.H.; Cheong, C.J.; Kim, S.J.; Seo, S.G.; Park, Y.K.; Jung, S.C. Contribution of Dissolved Oxygen to Methyl Orange Decomposition by Liquid Phase Plasma Processes System. Ozone Sci. Eng. 2014, 36, 244-248. [CrossRef]

15. Sato, M. Environmental and biotechnological applications of high-voltage pulsed discharges in water. Plasma Sour. Sci. Technol. 2008, 17, 024021-024027. [CrossRef]

16. Reddy, P.M.K.; Subrahmanyam, C. Green Approach for Wastewater Treatment-Degradation and Mineralization of Aqueous Organic Pollutants by Discharge Plasma. Ind. Eng. Chem. Res. 2012, 51, 11097-11103. [CrossRef]

17. Horikoshi, S.; Serpone, N. In-liquid plasma: A novel tool in the fabrication of nanomaterials and in the treatment of wastewaters. RSC Adv. 2017, 7, 47196-47218. [CrossRef]

18. Sunka, P.; Babicky, V.; Clupek, M.; Lukes, P.; Simek, M.; Schmidt, J.; Cernak, M. Generation of chemically active species by electrical discharges in water. Plasma Sour. Sci. Technol. 1999, 8, 258-265. [CrossRef]

19. Kang, J.; Li, O.L.; Saito, N. Synthesis of structure-controlled carbon nano spheres by solution plasma process. Carbon 2013, 60, 292-298. [CrossRef]

20. Tantiplapol, T.; Singsawat, Y.; Narongsil, N.; Damrongsakkul, S.; Saito, N.; Prasertsung, I. Influences of solution plasma conditions on degradation rate and properties of chitosan. Innov. Food Sci. Emerg. Technol. 2015, 32, 116-120. [CrossRef]

21. Hyun, K.; Ueno, T.; Saito, N. Synthesis of nitrogen-containing carbon by solution plasma in aniline with high-repetition frequency discharges. Jpn. J. Appl. Phys. 2016, 55, 01AE18. [CrossRef]

22. Sugiarto, A.T.; Sato, M. Pulsed plasma processing of organic compounds in aqueous solution. Thin Solid Films 2001, 386, 295-299. [CrossRef]

23. Alshamsi, F.A.; Albadwawi, A.S.; Alnuaimi, M.M.; Rauf, M.A.; Ashraf, S.S. Comparative efficiencies of the degradation of Crystal Violet using UV/hydrogen peroxide and Fenton's reagent. Dyes Pigment. 2007, 74, 283-287. [CrossRef] 
24. Locke, B.R.; Sato, M.; Sunka, P.; Hoffman, M.R.; Chang, J.S. Electrohydraulic Discharge and Nonthermal Plasma for Water Treatment. Ind. Eng. Chem. Res. 2006, 45, 882-905. [CrossRef]

25. Elliot, A.J.; McCracken, D.R. Estimation of Rate Constants for Near-diffusion-controlled Reactions in Water at High Temperatures. J. Chem. Soc. Faraday Trans. 1990, 86, 1539-1547. [CrossRef]

26. Alnaizy, R.; Akgerman, A. Advanced oxidation of phenolic compounds. Adv. Environ. Res. 2000, 4, $233-244$. [CrossRef]

27. Cheng, H.H.; Chen, S.S.; Wu, Y.C.; Ho, D.L. Non-Thermal Plasma Technology for Degradation of Organic Compounds in Wastewater Control: A Critical Review. J. Environ. Eng. Manag. 2007, 17, 427-433.

28. Hao, X.L.; Zhou, M.H.; Zhang, Y.; Lei, L.C. Enhanced degradation of organic pollutant 4-chlorophenol in water by non-thermal plasma process with $\mathrm{TiO}_{2}$. Plasma Chem. Plasma Process. 2006, 26, 455-468. [CrossRef]

29. Mukherjee, D.; Ray, A.K.; Barghi, S. Mechanism of Acetyl Salicylic Acid (Aspirin) Degradation under Solar Light in Presence of a $\mathrm{TiO}_{2}$-Polymeric Film Photocatalyst. Processes 2016, 4, 13. [CrossRef]

30. Li, L.; Ma, Q.; Wang, S.; Song, S.; Li, B.; Guo, R.; Cheng, X.; Cheng, Q. Photocatalytic Performance and Degradation Mechanism of Aspirin by $\mathrm{TiO}_{2}$ through Response Surface Methodology. Catalysts 2018, 8, 118. [CrossRef]

31. Dai, Q.; Xia, Y.; Jiang, L.; Li, W.; Wang, J.; Chen, J. Enhanced Degradation of Aspirin by Electrochemical oxidation with Modified $\mathrm{PbO}_{2}$ Electrode and Hydrogen Peroxide. Int. J. Electrochem. Sci. 2012, 7, 12895-12906.

32. Cui, Y.; Meng, Q.; Deng, X.; Ma, Q.; Zhang, H.; Cheng, X.; Li, X.; Xie, M.; Cheng, Q. Fabrication of platinum nano-crystallites decorated $\mathrm{TiO}_{2}$ nano-tube array photoelectrode and its enhanced photoelectrocatlytic performance for degradation of aspirin and mechanism. J. Ind. Eng. Chem. 2016, 43, 177-184. [CrossRef]

33. Wang, W.; Zhu, Q.; Qin, F.; Dai, Q.; Wang, X. Fe doped $\mathrm{CeO}_{2}$ nanosheets as Fenton-like heterogeneous catalysts for degradation of salicylic acid. Chem. Eng. J. 2018, 333, 226-239. [CrossRef]

(C) 2019 by the authors. Licensee MDPI, Basel, Switzerland. This article is an open access article distributed under the terms and conditions of the Creative Commons Attribution (CC BY) license (http://creativecommons.org/licenses/by/4.0/). 